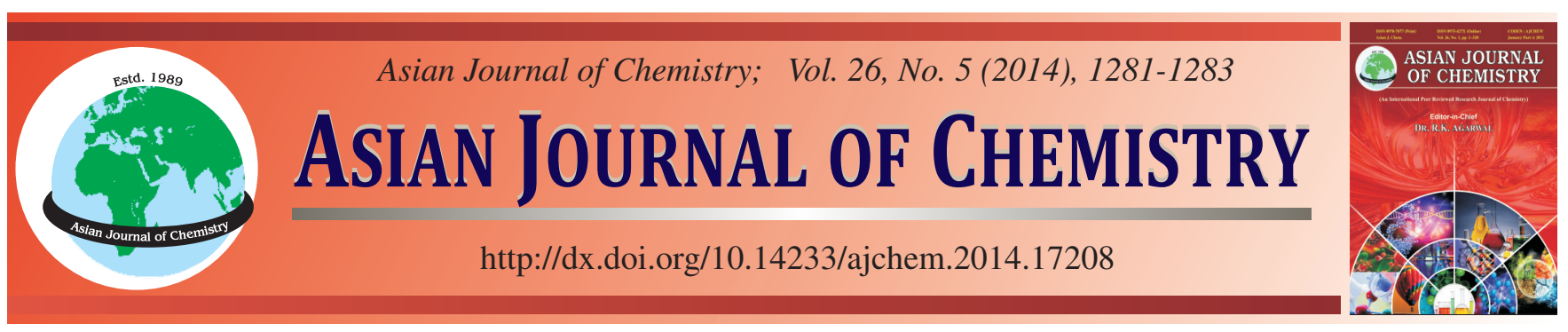

\title{
Flowability and Strength Characteristics Based on Replacement Rate of Admixture Material for Modified Sulphur Mortar $\dagger$
}

\author{
SANGSOo LeE*, Hayoung Song and ByeOngyeol Jung
}

Department of Architectural Engineering, Hanbat National University, Daejeon 305-719, Republic of Korea

*Corresponding author: Fax: +82 42 8211590; E-mail: sslee111@hanbat.ac.kr

This study compared the flowability and strength characteristics of mortar based on the replacement rate of fly ash, silica fume and blast furnace slag which were the admixture materials for the modified sulphur mortar. The flowability increased when the admixture material was substituted for the modified sulphur mortar. The silica fume showed the highest strength in terms of flexural strength and compressive strength, followed by the blast furnace slag and fly ash.

Keywords: Flowability, Modified sulphur, Silica fume, Blast furnace slag, Fly ash.

\section{INTRODUCTION}

Korea has seen the surge in the fuel consumption, including the oil and natural gas, since the development of industry in the 1970s and as a result, there has been an increase in industrial sulphur generation ${ }^{1}$. The generation of industrial sulphur has skyrocketed amid the advancement of crude oil refining and desulphurization technology. Current generation of sulphur is above 120 ten thousand ton As the consumption of crude oil increases, the production of sulphur is expected to continue growth in the period ahead. $50 \%$ of sulphur produced every year is used mostly in fertilizer, chemicals, cosmetics and asphalt, etc. and the remaining sulphurs are exported to China, Japan and other countries ${ }^{2}$. The production of sulphur is expected to soar due to the expansion of oil refining facilities and advancement of oil refining facilities worldwide.

It has been a well-known fact that the sulphur concrete, produced by using the sulphur as binder, instead of cement, has excellent characteristics, particularly, the rapid hardening, acid resistance and chemical resistance among other concretes $^{3}$.

However, the sulphur concrete production requires the maintenance of temperature at over $130{ }^{\circ} \mathrm{C}$, which makes the production difficult. Therefore, the sulphur concrete was used mainly for Hume pipes, the precast concrete product, or railway sleepers, etc.
Recently, the modified sulphur was developed by the "Company H", a Korea enterprise, which lowered the melting point of sulphur to approximately $65 \pm 5^{\circ} \mathrm{C}$. Thus, this study will provide the basis for using the sulphur concrete or sulphur mortar by using the modified sulphur and admixture material which have the melting point of $65 \pm 5^{\circ} \mathrm{C}$.

\section{EXPERIMENTAL}

This study intented to determine the basic performance of the mortar that mixed the modified sulphur with the byproducts such as blast furnace slag, fly ash and silica fume. The fly ash, blast furnace slag and silica fume were substituted with $0,10,20$ and $30 \%$ based on the weight ratio of cement. The addition ratio of modified sulphur was $10 \%$ of the weight of binder and the W/B was 0.5 . The mixing rate is presented in Table-1.

The modified sulphur, developed by "Company H" of Korea, was used in this study. This modified sulphur exists in a semi-solid state at room temperature. The amount of sulphur and dicyclopentadiene (DCPD) was 1:1 on the basis of molar ratio. For the pyridine, the polymer which comprise $1 \%$ of total weight was used. The modified sulphur used in the experiment was the liquid phase dissolved at $65 \pm 5^{\circ} \mathrm{C}$. Regarding the chemical composition, sulphur makes up $97 \%$ of the modified sulphur. The density of this modified sulphur was $2 \mathrm{~g} / \mathrm{cm}^{3}$. For cement, ordinary portland cement was used which was produced by 'Company H', and conforms to the 


\begin{tabular}{|c|c|c|c|c|c|c|c|}
\hline \multicolumn{8}{|c|}{$\begin{array}{c}\text { TABLE-1 } \\
\text { MIX DESIGN }\end{array}$} \\
\hline \multirow{2}{*}{ W/B } & \multirow{2}{*}{ Water (g) } & \multicolumn{4}{|c|}{ Binder $(\mathrm{g})$} & \multirow{2}{*}{$S^{(e)}(g)$} & \multirow{2}{*}{$\mathrm{MS}^{(\mathrm{f})}(\mathrm{g})$} \\
\hline & & $\mathrm{OPC}^{(\mathrm{a})}$ & $\mathrm{BFS}^{(\mathrm{b})}$ & $\mathrm{FA}^{(\mathrm{c})}$ & $\mathrm{SF}^{(\mathrm{d})}$ & & \\
\hline \multirow{10}{*}{0.5} & \multirow{10}{*}{500} & 1000 & - & - & - & \multirow{10}{*}{3000} & \multirow{10}{*}{100} \\
\hline & & 900 & 100 & - & - & & \\
\hline & & 800 & 200 & - & - & & \\
\hline & & 700 & 300 & - & - & & \\
\hline & & 900 & - & 100 & - & & \\
\hline & & 800 & - & 200 & - & & \\
\hline & & 700 & - & 300 & - & & \\
\hline & & 900 & - & - & 100 & & \\
\hline & & 800 & - & - & 200 & & \\
\hline & & 700 & - & - & 300 & & \\
\hline
\end{tabular}

(a) OPC: Ordinary portland cement, (b) BFS: Blast furnace slag, (c) FA: Fly ash, (d) SF: Silica fume, (e) S: Fine aggregate, (f) MS: Modified sulphur.

standards of KS L 5021. The washed sand was used for fine aggregates. The density was $2.61 \mathrm{~g} / \mathrm{cm}^{3}$ and the fineness modulus was 2.70 .

The chemical composition of the admixture material used in this study is presented in Table-2. The fly ash was produced by 'Company D', a Korea enterprise, had a density of $2.22 \mathrm{~g} /$ $\mathrm{cm}^{3}$ and fineness of $4,124 \mathrm{~cm}^{2} / \mathrm{g}$. The blast furnace slag (BFS) used in this study was the product of "G Corporation", a Korea company, had a density of $2.91 \mathrm{~g} / \mathrm{cm}^{3}$ and fineness of 4,464 $\mathrm{cm}^{2} / \mathrm{g}$. The silica fume used in this study was the product of "C Corporation", an overseas company, had a density of 2.30 $\mathrm{g} / \mathrm{cm}^{3}$ and fineness of $220,000 \mathrm{~cm}^{2} / \mathrm{g}$.

Test method: Cement, admixture material and fine aggregates were put inside and mixed in a dry state for $90 \mathrm{~s}$. Then, the mixing water was poured in and the materials inside were mixed for another $90 \mathrm{~s}$. The modified sulphur in a liquid state, heated to $65 \pm 5^{\circ} \mathrm{C}$ in the heating pan, was mixed for $60 \mathrm{~s}$ and then discharged.

\section{RESULTS AND DISCUSSION}

Flowability and air content: In this experiment, the flowability was measured based on the replacement rate of the by-product of modified sulphur cement. The results are presented in Fig. 1. The flowability was the highest in the blast furnace slag with the replacement rate of $10 \%$. Compared to the ordinary portland cement, the flowability increased by 34 $\%$. The fly ash with the replacement rate of $10 \%$ showed an increase of flowability by $21 \%$, while the flowability rose by ca. $13 \%$ in the silica fume which had the replacement rate of $10 \%$. That is considered to be attributable to the higher fineness of the admixture material compared to the cement, resulting in the decreased flowability. Particularly, the flowability of silica fume is considered to be lower, compared to ordinary portland cement, in case of the replacement rate of $30 \%$ because the silica fume has high fineness.

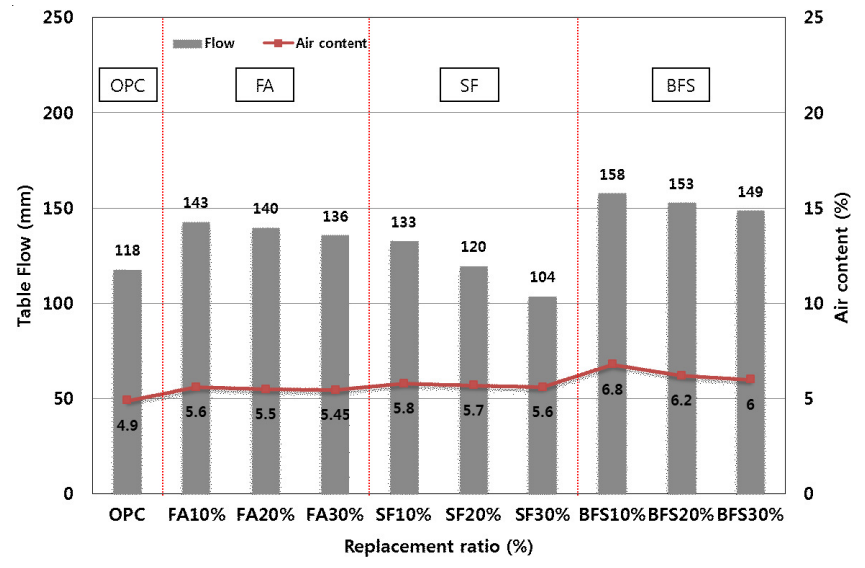

Fig. 1. Flowability and air content based on replacement rate of admixture material for modified sulphur mortar

Fig. 1 shows the air content based on the replacement rate of admixture material. The air content was measured immediately after the mixing process. The results of measurement showed that the air content decreased gradually as the replacement rate increased.

Flexural strength: Fig. 2 shows the flexural strength based on the replacement rate of admixture material. The cement and admixture material that showed the highest strength in terms of flexural strength were in the order of the silica fume, blast furnace slag, ordinary portland cement and fly ash. For the silica fume, the flexural strength increased as the replacement rate rose to 10,20 and $30 \%$. The blast furnace slag with the replacement rate of $20 \%$ had higher strength, compared to that with the replacement rate of $30 \%$, in the $3 \mathrm{rd}$ day. However, the blast furnace slag with the replacement rate of $30 \%$ had higher strength, compared to that with the replacement rate of $20 \%$, in the 7 days and 28 days. The fly ash showed a tendency that its strength rose with the replacement rate of up to $20 \%$, but declined when the

TABLE-2

CHEMICAL COMPONENT OF ADMIXTURE MATERIAL

\begin{tabular}{lccccccc}
\hline \multirow{2}{*}{ Admixture materials } & \multicolumn{9}{c}{ Chemical component (\%) } \\
\cline { 2 - 9 } & $\mathrm{SiO}_{2}$ & $\mathrm{Al}_{2} \mathrm{O}_{3}$ & $\mathrm{Fe}_{2} \mathrm{O}_{3}$ & $\mathrm{CaO}$ & $\mathrm{MgO}$ & $\mathrm{SO}_{3}$ & $\mathrm{TiO}_{2}$ \\
\hline Fly ash & 54.38 & 21.50 & 5.16 & 10.83 & 1.89 & 1.29 & 0.62 \\
Blast furnace slag & 26.03 & 10.96 & 0.18 & 54.07 & 4.21 & 3.28 & 0.22 \\
Silica fume & 94.00 & 2.60 & 1.69 & 0.31 & 1.03 & 0.15 & - \\
\hline
\end{tabular}




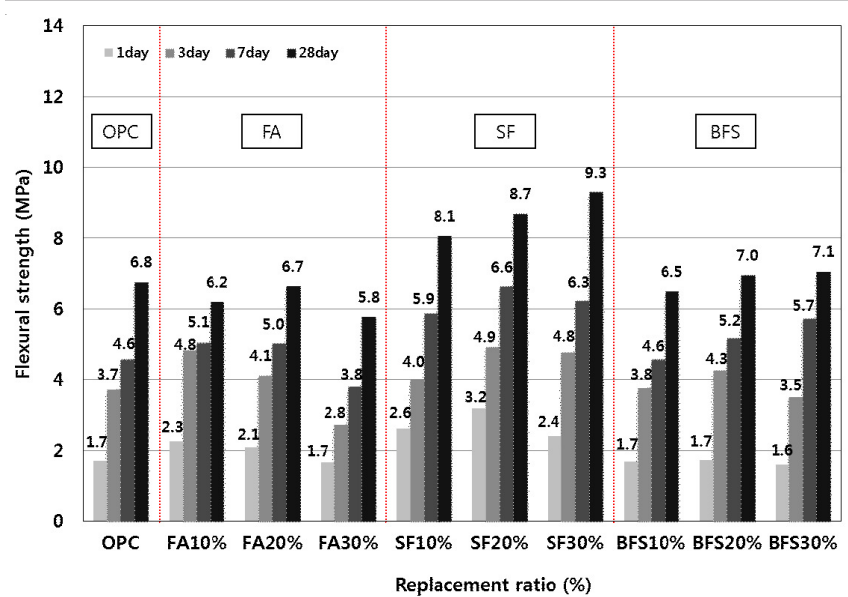

Fig. 2. Flexural strength based on replacement rate of admixture material for modified sulphur mortar

replacement rate was $30 \%$. The fly ash in the 28 days had the flexural strength $0.1 \mathrm{MPa}$ lower than the ordinary portland cement which was added with $10 \%$ modified sulphur. It was found that the fly ash did not have an effect on the increase of flexural strength. The flexural strength in the 3 days decreased without exception when the replacement rate of all admixture materials used in this experiment was $30 \%$. It suggest that the use of excessive amount of admixture materials may affect the initial strength development.

Compressive strength: Fig. 3 shows the compressive strength based on the age, depending on the replacement rate of admixture material. Higher strength was manifested in all test specimens, compared to the strength of ordinary portland cement, when the admixture material was substituted. For the fly ash, the strength decreased as the replacement rate increased in the 3 days. The silica fume showed the strength increasing proportionally to the replacement rate. For the blast furnace slag, the strength increased to 10 and $20 \%$, but declined slightly when the replacement rate was $30 \%$. In the 28 days, all of the fly ash, silica fume and blast furnace slag showed the tendency same as that manifested in the 3 days.

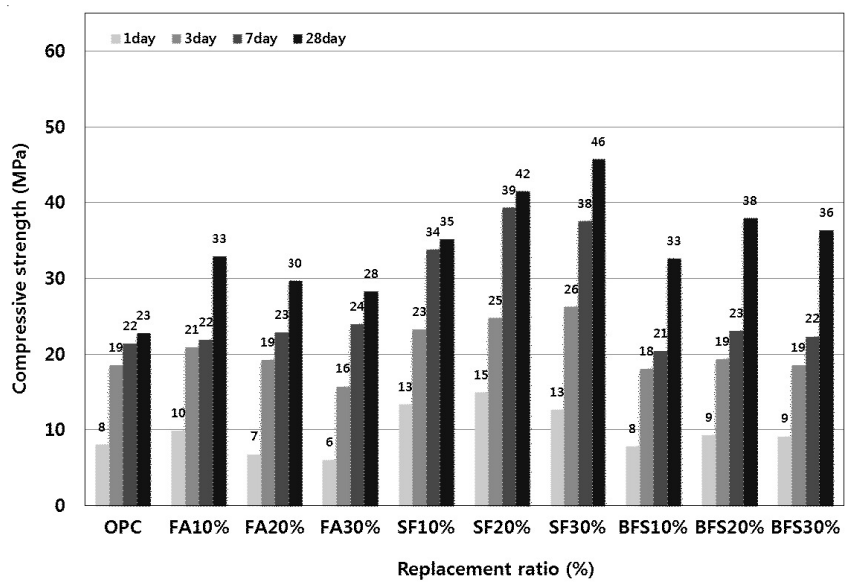

Fig. 3. Compressive strength based on replacement rate of admixture material for modified sulphur mortar
The proper replacement rate of admixture material might be $10 \%$ for fly ash, $30 \%$ for silica fume and $20 \%$ for blast furnace slag. Such results are considered attributable to the fact that the rate of rise in strength was very steep in the 28 days than in the 7 days due to the pozzolanic reaction in the case of fly ash.

The silica fume is the ultra-fine particle with the fineness of $220,000 \mathrm{~cm}^{2} / \mathrm{g}$ and showed high strength development as the reaction started quickly from the 3 days due to the rapid pozzolanic reaction and void filling. The blast furnace slag had the hydraulic property leading to the significant difference in the strength development in the 7 days and 28 days.

\section{Conclusion}

The researchers relate to the characteristics of the flowability and strength in mortar that substituted the admixture material for the modified sulphur mortar. The air content decreased gradually as the replacement rate of admixture material increased. The replacement rate of admixture material which resulted in higher flowability was $10 \%$. The flowability increased by $34 \%$ in blast furnace slag, compared to ordinary portland cement. The increase in the flowability was $21 \%$ for fly ash and $13 \%$ for silica fume. The replacement rate of admixture material which led to the highest flexural strength was $20 \%$ for fly ash, $30 \%$ for silica fume and $30 \%$ for blast furnace slag based on admixture material. The replacement rate of admixture material which led to the highest compressive strength was $30 \%$ for silica fume, $20 \%$ for blast furnace slag and $10 \%$ for fly ash based on admixture material. $10 \%$ of test specimens showed high strength development when the replacement rate was $20 \%$ for blast furnace slag and $10 \%$ for fly ash.

\section{ACKNOWLEDGEMENTS}

This paper expresses thanks because of being performed in 2012 supported from Ministry of Knowledge Economy venture type speciality introduction technology development business [:10043146 ] link.

\section{REFERENCES}

1. J.H. Yoon and H.S. Heo, An Experimental Study on the Manufacturing of Sulfur Mortar, Korea Institute of Building Construction, vol. 11, pp. 93-6 (2003).

2. S.W. Cha, K.S. Kim and H.S. Park, Manufacture of Modified Sulfur Polymer Binder and Characteristics of Sulfur Concrete, Korea Concrete Institute, vol. 23, pp. 40-43 (2011).

3. D.J. Kim, Master's thesis, An Experimental Study on the Manufacturing Sulfur Concrete, Suwon University, Suwon, Korea, pp 1-104 (2002). 